\title{
Smoking and environmental characteristics of smokers with a mental illness, and associations with quitting behaviour and motivation; a cross sectional study
}

Alexandra P. Metse ${ }^{1,2^{*}}$, John Wiggers ${ }^{1,2,3}$, Paula Wye ${ }^{1,2,3}$, Lyndell Moore ${ }^{1,2}$, Richard Clancy ${ }^{1,2,4}$, Luke Wolfenden ${ }^{1,2,3}$, Megan Freund ${ }^{1,2}$, Tara Van Zeist ${ }^{1,2}$, Emily Stockings ${ }^{5}$ and Jenny A. Bowman ${ }^{1,2}$

\begin{abstract}
Background: Persons with a mental illness are less likely to be successful in attempts to quit smoking. A number of smoking and environmental characteristics have been shown to be related to quitting behaviour and motivation of smokers generally, however have been less studied among smokers with a mental illness. This study aimed to report the prevalence of smoking characteristics and a variety of physical and social environmental characteristics of smokers with a mental illness, and explore their association with quitting behaviour and motivation.

Methods: A cross-sectional descriptive study was undertaken of 754 smokers admitted to four psychiatric inpatient facilities in Australia. Multivariable logistic regression analyses were undertaken to explore the association between smoking and environmental characteristics and recent quitting behaviour and motivation.

Results: Participants were primarily daily smokers (93\%), consumed $>10$ cigarettes per day (74\%), and highly nicotine dependent (51\%). A third (32\%) lived in a house in which smoking was permitted, and $44 \%$ lived with other smokers. The majority of participants believed that significant others (68-82\%) and health care providers (80-91\%) would be supportive of their quitting smoking. Reflecting previous research, the smoking characteristics examined were variously associated with quitting behaviour and motivation. Additionally, participants not living with other smokers were more likely to have quit for a longer duration (OR 2.02), and those perceiving their psychiatrist to be supportive of a quit attempt were more likely to have had more quit attempts in the past six months (OR 2.83).
\end{abstract}

Conclusions: Modifiable characteristics of the physical and social environment, and of smoking, should be considered in smoking cessation interventions for persons with a mental illness.

Keywords: Smoking, Mental illness, Characteristics, Social, Environment, Quitting, Quitting motivation

\section{Background}

A decreased likelihood of successfully quitting $[1,2]$ contributes to the persistently higher prevalence of smoking among persons with a mental illness [3-6]. This in turn is reflected in greater morbidity and mortality from tobaccorelated diseases and a reduced life expectancy $[7,8]$.

\footnotetext{
* Correspondence: alexandra.metse@uon.edu.au

${ }^{1}$ University of Newcastle, University Drive, Callaghan, NSW 2308, Australia ${ }^{2}$ Hunter Medical Research Institute, Lot 1 Kookaburra Circuit, New Lambton Heights, NSW 2305, Australia

Full list of author information is available at the end of the article
}

Successful smoking cessation is often preceded by multiple quit attempts $[9,10]$, a motivation to quit $[9,11]$, and a greater capacity to identify as a potential non-smoker [12-14]. The likelihood of being motivated and attempting to quit has been suggested to be a function of an individual's smoking characteristics such as level of nicotine dependence $[15,16]$, number of cigarettes smoked per day $[17,18]$, age of smoking initiation $[10,19]$, and number of years smoking [20]. While research among smokers with a mental illness specifically has consistently demonstrated high levels of nicotine dependence and heavy smoking (in terms of cigarettes per day) $[3,5,6]$, far less research has 
explored the associations of such characteristics with quitting behaviour and motivation. That which has been undertaken however suggests the same patterns of association as found among smokers generally [11, 21, 22]. For instance, lower levels of nicotine dependence have been associated with quit attempts of longer duration ( $>7$ days) among smokers from the United States (U.S.) attending a residential substance treatment program [22], and following discharge from a psychiatric inpatient facility [11].

Socio-ecological theories also highlight the potential influence of a range of broader physical and social environmental characteristics of smokers on quitting behaviour [23]. Among smokers generally, characteristics associated with both attempts to quit and successful cessation include: residing in a smoke-free home [10, 24, 25]; absence of persons who smoke in the immediate environment [10, 25]; a partner being a non-smoker [26, 27]; and perception of support to quit from significant others [28, 29] and health care providers $[16,30]$. Consequently, intervention strategies to aid smoking cessation have included: the introduction of smoke-free workplace policies [31]; enhancement of partner support for spouse's smoking cessation [32]; smoking cessation care being delivered by health care providers [33]; and increasing the availability of smoking cessation peer support programs [34].

Very little research has explored the prevalence of such physical and social environmental characteristics among persons with a mental illness. In the U.S., a study reported that only $24 \%$ of smokers diagnosed with psychotic or mood disorders occupied a residence where smoking was not permitted inside [35], nearly half that reported in a national representative sample of smokers without a mental illness (46\%) [36]. Among clients of U.S. community mental health services, the proportion of smokers with acquaintances that smoked was more than twice that of nonsmokers (78 \% vs $35 \%$ ) and smokers were reported to have higher rates of household second-hand smoke exposure (47 \% vs $28 \%$ ) [37]. In one Australian study, the proportion of smokers with a mental illness living in a smoke-free home was found to be $42 \%$, almost $20 \%$ less than those without a mental illness [38].

In addition, few studies have explored the association between the physical and social environmental characteristics of smokers with a mental illness and their quitting behaviour and motivation. In one such study, among U.S. smokers with co-occurring severe mental illness and substance use disorders, Ferron et al. [39] found that more social contact with non-substance using (including tobacco) friends was positively associated with a higher number of quit attempts. Survey data from the United Kingdom (UK) [40] and U.S. [41] similarly suggest that aspects of the physical and social environment have an impact on smoking and quitting behaviour of smokers with a mental illness. Among recent quitters with a current mental illness,
46-58 \% identified social support to quit from friends, family and doctors as key enabling factors in their successful quitting [41]; and among forensic psychiatric inpatients, exposure to others smoking and lack of encouragement from psychiatric staff to quit were identified as barriers to successful smoking cessation [40]. Further, qualitative research undertaken in several countries, including g the U.S. [42, 43], UK [44], Scotland [45], Australia [46], and Canada [47], has suggested that a lack of support to quit from family and friends [44] and health care professionals [43-46], and socialising with other smokers $[42,45,47]$ contribute to continued smoking by this group.

Given the limited evidence available, it is suggested that a greater understanding of the characteristics of smokers with a mental illness that are associated with their quitting behaviour and motivation [48] is required to facilitate the development of effective smoking cessation interventions. We conducted a study that aimed to 1) report the prevalence of smoking characteristics and a variety of physical and social environmental characteristics of smokers with a mental illness and 2) explore the association between such characteristics and recent quitting behaviour and motivation.

\section{Methods \\ Design and setting}

A cross-sectional descriptive study was undertaken in the context of a smoking cessation intervention trial [49] conducted in four adult psychiatric inpatient facilities in New South Wales (NSW), Australia.

\section{Sample and recruitment procedure}

Research staff approached all patients admitted to the four psychiatric inpatient facilities over a 19 month period (October 2012 and April 2014) to assess for study eligibility [49]. Research staff were independent of the hospitals, received standardised training in mental illness and its impacts, and had completed or were in the process of completing an undergraduate degree in a health related area. Patients eligible for the trial were: current smokers (smoked tobacco in the month prior to admission); at least 18 years of age; willing to provide contact details; and able to give informed consent to participate in the trial. No other exclusion criteria were applied.

\section{Ethics, consent and permissions}

Ethics approval was obtained from the Hunter New England Human Research Ethics Committee (reference no: 11/12/ 14/4.02) and the University of Newcastle Human Research Ethics Committee (reference no: H-2012-0061). Written consent was obtained from all participants.

\section{Data collection procedures}

Consenting participants completed a face-to-face structured interview, administered by research staff during their 
hospital stay. Interviews were administered in a quiet area of the inpatient unit and took approximately $40 \mathrm{~min}$ to complete. Participants could opt to have short breaks during the data collection process as required. Interviews were carried out prior to participant allocation to the intervention or usual care control condition of the overarching smoking trial [49]. Characteristics of smoking and of the participants' physical and social environment relevant to smoking, and recent quitting behaviour and motivation were collected by the interview. Participant clinical and demographic information was obtained via the facility electronic medical record system and the participant interview.

\section{Measures \\ Clinical and demographic information}

The following participant data were collected from the patient medical record system: age, gender, relationship status (single, married/de facto, separated/divorced, widowed, did not state/inadequately described), Aboriginal and/or Torres Strait Islander status (Aboriginal and/or Torres Strait Islander, neither, did not state), primary mental health diagnosis at discharge (schizophrenia and related psychoses, anxiety and stress related disorders, mood disorders, substance- related disorders, personality and other disorders), legal status at admission (voluntary, involuntary), and length of stay (total days between admission and discharge).

The following clinical and demographic information was obtained from the participant interview: level of alcohol use (AUDIT-C) [50], education (primary school, third year of high school, school certificate (fourth year high school), Higher School Certificate [HSC] (sixth year high school), TAFE certificate or diploma (tertiary qualification not obtained from a university), bachelor degree, post graduate degree), employment details (full time, part time, household duties, student, unemployed/other), receipt of a government payment (yes, no), and living circumstances (on own, with others).

\section{Smoking characteristics}

The smoking characteristics of participants prior to admission were: smoking status (daily smoker, weekly smoker, irregular smoker [smoked cigarettes less than weekly), cigarettes per day, level of nicotine dependence (Fagerstrom Test for Nicotine Dependence [FTND]) [51], age initiated smoking, and number of years smoked.

\section{Physical and social environmental characteristics}

Participants were asked if they: lived in a smoke-free house prior to admission (a place of residence where smoking is not permitted inside; yes, no), lived with smokers prior to admission (lived with at least one other smoker; yes, no), and had a partner who smoked (partner smokes, partner does not smoke/no partner).

Participants were also asked to rate on a seven point Likert- type scale ('very supportive' to 'actively discourage, 'unsure' and 'not applicable'), how supportive they perceived the following persons would be if they were to attempt to quit smoking: partner, family, friends, general practitioner (primary care physician; GP), psychiatrist, and 'other' mental health professional (psychologists, social workers, nurses, counsellors and case managers). Participants were asked if they had someone in their life they felt was their key support person (a person of whom they could rely and/or routinely provided assistance and general support; yes, no).

\section{Recent quitting behaviour and motivation}

Measures of recent quitting behaviour were: a quit attempt in past six months (yes, no); and, for those who had attempted to quit in the past six months, the number of times (once, two to three times, more than three times) and duration of longest quit attempt in that period (days). Quit attempts were defined as not smoking on purpose for a period of at least $24 \mathrm{~h}$, with the intention of quitting smoking [52].

Measures of smoking related motivation were: readiness to quit and smoking identity. To assess current readiness to change, the Readiness to Quit Smoking Questionnaire [53] was used, eliciting responses to five items in a Likert scale format. Smoking identity was measured using a single question asking respondents to indicate how easy it was for them to see themselves as a non-smoker [14]. Participants responded on a five point Likert- type scale ranging from very easy to very difficult, with an 'unsure' option.

\section{Analysis}

Data were analysed using SPSS Statistics version 22 [54]. The following numerical variables were transformed to categorical variables for the purpose of association analyses: cigarettes per day $(1-10,11-20,21-30,>31)$ [55], age initiated smoking ( $<14$ years, $\geq 14$ years) [56], number of years smoked ( $\leq 10,11-20,>20$ years) [20], number of quit attempts in the past six months $(1, \geq 2)[9,57]$, and duration of longest quit attempt in the last six months (<1 month, $\geq 1$ month) $[10,57]$.

The following variables were categorised to two levels: smoking status (daily smoker, weekly/irregular smoker), nicotine dependence (low-moderate [FTND score $\leq 5$ ], high [FTND score $\geq 6$ ]) [58], readiness to quit (pre-contemplative, contemplative or a more progressed stage), and ease of seeing self as a non-smoker (easy, difficult/unsure). All measures pertaining to the degree of perceived social support to quit smoking from significant persons/ clinicians were also categorised to two levels (supportive, unsupportive/unsure/not applicable). 
Participant clinical and demographic information, smoking and physical and social environmental characteristics, and recent quitting behaviour and motivation were summarised using descriptive statistics.

Chi-square analysis was used to explore univariate associations between each separate smoking and physical and social environmental characteristic, and recent quitting behaviour and motivation. Variables with a $p$-value of $\leq 0.25$ were subsequently entered into multivariable logistic regression models, using both backward elimination and stepwise variable selection to ensure model stability. Significance level was set at 0.05 for the inclusion of variables in the final models. Separate models were developed for five dependent variables: quit attempt in the past six months (yes, no), number of quit attempts in past six months (one, two or more), duration of quit attempt in the past six months ( $<1$ month, $\geq 1$ month), readiness to quit (pre-contemplative, contemplative or a more progressed stage), and ease of seeing self as a non-smoker (easy, difficult/unsure).

\section{Results}

Sample

Of the 3626 patients admitted to the four inpatient facilities in the study period, $64 \%(n=2315)$ were approached by research staff. For those not approached, the primary reasons for non-contact were a short length of stay ( $\leq$ one night; $38 \%$ ) and psychiatric instability for the duration of time spent as an inpatient (35\%). Of the 2315 patients approached, 2078 (90\%) agreed to be assessed for study eligibility, of which 841 (40\%) were ineligible, predominantly due to being non-smokers $(n=797,95 \%)$. Sixty one per cent $(n=754)$ of eligible smokers consented and completed the survey (Fig. 1).

\section{Patient clinical and demographic information}

Table 1 describes the clinical and demographic characteristics of patients approached and not approached, and participants and non-consenters. Approximately one third (30\%) of participants lived on their own, $66 \%$ with a partner or with others, and $4 \%$ reported being homeless (not in table).

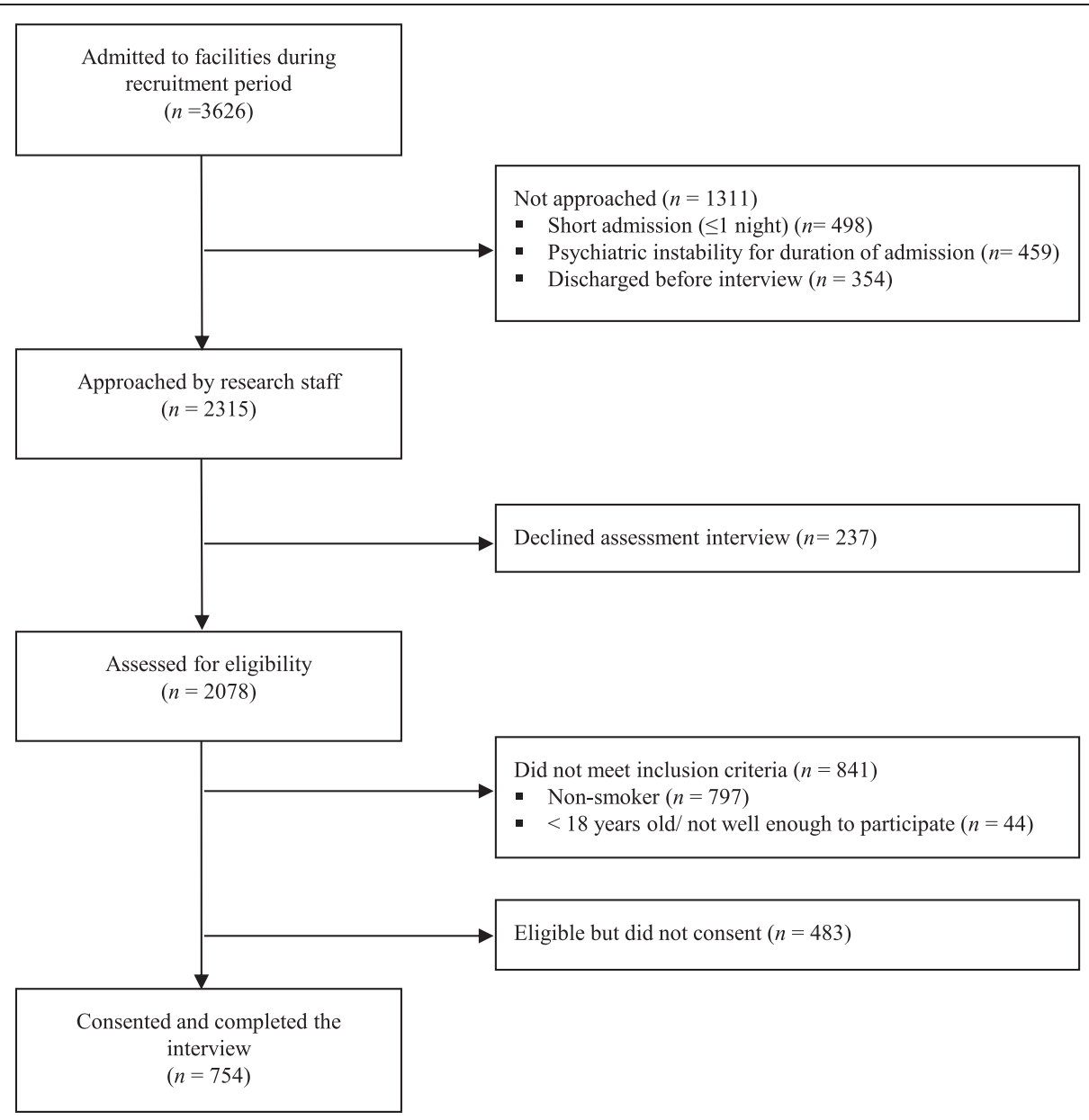

Fig. 1 Flow diagram illustrating the number of patients approached, assessed for eligibility and recruited into the study 
Table 1 Clinical and demographic characteristics of not approached and approached patients, and participants and non-consenters

\begin{tabular}{|c|c|c|c|c|}
\hline & $\begin{array}{l}\text { Not approached } \\
(N=1311)\end{array}$ & $\begin{array}{l}\text { Approached } \\
(N=2315)\end{array}$ & $\begin{array}{l}\text { Non-consenters } \\
(N=483)\end{array}$ & $\begin{array}{l}\text { Participants } \\
(N=754)\end{array}$ \\
\hline \multicolumn{5}{|l|}{ Gender (\%) } \\
\hline Male & 60.0 & 55.4 & 63.4 & 61.3 \\
\hline Female & 40.0 & 44.6 & 36.6 & 38.7 \\
\hline \multicolumn{5}{|l|}{ Age (years) } \\
\hline Mean (SD) & $39.8(17.1)$ & $41.8(14.2)$ & $38.9(11.7)$ & $38.7(12.0)$ \\
\hline Median (range: min-max) & $37(10-94)$ & $41(18-93)$ & $38(18-82)$ & $38(18-76)$ \\
\hline \multicolumn{5}{|l|}{ Relationship status (\%) } \\
\hline Single & 59.0 & 58.6 & 70.8 & 63.7 \\
\hline Married/de facto & 25.7 & 24.1 & 17.4 & 20.7 \\
\hline Separated/divorced/widowed & 14.2 & 16.5 & 10.8 & 15.0 \\
\hline Not stated/inadequately described & 1.0 & 0.7 & 1.0 & 0.7 \\
\hline \multicolumn{5}{|l|}{ Aboriginal and/or Torres Strait Islander Status (\%) } \\
\hline Aboriginal and/or Torres Strait Islander & 12.8 & 11.6 & 17.7 & 13.5 \\
\hline Neither Aboriginal or Torres Strait Islander/unknown & 87.2 & 88.4 & 82.3 & 86.5 \\
\hline \multicolumn{5}{|l|}{ Employment status (\%) } \\
\hline Full time & - & - & - & 15.1 \\
\hline Part time & - & - & - & 11.4 \\
\hline Student & - & - & - & 2.8 \\
\hline Unemployed/household duties/other & - & - & - & 70.7 \\
\hline \multicolumn{5}{|l|}{ Highest education level achieved (\%) } \\
\hline Up to third year of high school & - & - & - & 28.4 \\
\hline School Certificate & - & - & - & 32.6 \\
\hline Higher School Certificate (HSC) & - & - & - & 13.4 \\
\hline Tertiary & - & - & - & 25.6 \\
\hline \multicolumn{5}{|l|}{ Receipt of a government payment (\%) } \\
\hline Yes & - & - & - & 77.1 \\
\hline No & - & - & - & 22.9 \\
\hline \multicolumn{5}{|l|}{ Diagnosis type (\%) } \\
\hline Schizophrenia and related psychosis & 14.1 & 27.6 & 37.1 & 19.5 \\
\hline Anxiety and stress related disorders & 20.3 & 8.5 & 6.4 & 13.0 \\
\hline Mood disorders & 23.1 & 30.8 & 22.4 & 26.7 \\
\hline Substance related disorders & 21.2 & 15.6 & 18.0 & 23.1 \\
\hline Personality and other disorders & 21.3 & 17.4 & 16.1 & 17.8 \\
\hline \multicolumn{5}{|l|}{ Alcohol use (AUDIT- C) (\%)* } \\
\hline Harmful/hazardous & - & - & - & 64.5 \\
\hline Non-harmful/hazardous & - & - & - & 35.5 \\
\hline \multicolumn{5}{|l|}{ Length of stay (days) } \\
\hline Mean (SD) & $12.4(62.1)$ & $16.8(28.7)$ & $17.6(24.4)$ & $14.3(17.9)$ \\
\hline Median (Range: min-max) & $2(0-1715)$ & $10(0-945)$ & $10(0-236)$ & $9(0-147)$ \\
\hline \multicolumn{5}{|l|}{ Legal status on admission (\%) } \\
\hline Voluntary & 55.6 & 53.2 & 49.3 & 53.2 \\
\hline Involuntary & 44.4 & 46.8 & 50.7 & 46.8 \\
\hline
\end{tabular}




\section{Prevalence of smoking characteristics}

Participants smoking characteristics are described in Table 2. Almost all (93\%) were daily smokers; $51 \%$ were assessed as highly nicotine dependent; nearly three quarters $(74 \%)$ smoked >10 cigarettes per day; $68 \%$ had commenced smoking before 16 years of age; and more than half (55\%) had smoked for more than 20 years.

\section{Prevalence of physical and social environmental characteristics}

Forty four per cent of participants lived with at least one other smoker, and $32 \%$ lived in a house where smoking was permitted inside (Table 3 ). Fifty one per cent of those with a partner reported that their partner smoked.

Almost all participants (92 \%) could identify a key support person in their life on whom they could rely and/or routinely provided assistance and general support. Seventy one per cent of participants with a partner believed the partner would be supportive of them making a quit attempt. Eighty two per cent and $68 \%$ of participants believed their family and friends would be supportive of them quitting, respectively. Eighty one, 91 and $80 \%$ of

Table 2 Smoking characteristics

\begin{tabular}{|c|c|}
\hline & Total $(N=754)$ \\
\hline \multicolumn{2}{|c|}{ Smoking status (\%) $)^{a, b}, c, d, e$} \\
\hline Daily & 93.0 \\
\hline Weekly & 3.6 \\
\hline Irregular & 3.4 \\
\hline \multicolumn{2}{|c|}{ Cigarettes Per Day (\%) } \\
\hline $1-10$ & 26.1 \\
\hline $11-20$ & 36.2 \\
\hline $21-30$ & 23.2 \\
\hline$>30$ & 14.5 \\
\hline \multicolumn{2}{|c|}{ Level of nicotine dependence $(\%)^{a, c, ~ e ~}$} \\
\hline Low-moderate & 48.8 \\
\hline High & 51.2 \\
\hline \multicolumn{2}{|c|}{ Age initiated smoking (\%) ${ }^{\text {d, e }}$} \\
\hline$<12$ & 21.8 \\
\hline $12-<14$ & 21.0 \\
\hline $14-<16$ & 25.2 \\
\hline $16-<18$ & 16.2 \\
\hline$\geq 18$ & 15.9 \\
\hline \multicolumn{2}{|c|}{ Number of years smoked (\%) } \\
\hline$\leq 10$ & 18.3 \\
\hline $11-20$ & 26.9 \\
\hline$>20$ & 54.8 \\
\hline
\end{tabular}

Entered into regression analyses: ${ }^{a}$ Quit attempt in the past 6 months; ${ }^{b}$ Number of quit attempts in the past 6 months; ' Length of longest quit attempt in past 6 months; ${ }^{d}$ Readiness to quit; ${ }^{e}$ Ease of seeing oneself as

a non-smoker
Table 3 Physical and social environmental characteristics

\begin{tabular}{ll}
\hline & $\%(n)^{\mathrm{a}}$ \\
\hline${\text { Lived with smokers (\%) })^{\mathrm{d}, \mathrm{e}}}$ & \\
Yes & $43.6(329)$ \\
No & $56.4(425)$ \\
Lived in a smoke-free house (\%) $^{\mathrm{d}}$ & \\
$\quad$ Yes & $68.0(513)$ \\
No & $32.0(241)$ \\
Partner smoking status (\%) $)^{\mathrm{e}}$ & \\
Partner smokes & $50.6(79)$ \\
Partner does not smoke & $49.4(77)$ \\
Identify a key support person (\%) & \\
Yes & $92.4(697)$ \\
No & $7.6(57)$
\end{tabular}

Perceived social support to quit smoking from:

Partner (\%) $)^{d, e}$

Supportive

$71.2(111)$

Unsupportive

$28.2(44)$

Unsure

$0.6(1)$

Family $(\%)^{f}$

Supportive

$82.3(552)$

Unsupportive

$8.9(60)$

Unsure

Friends (\%)

Supportive

$68.0(433)$

Unsupportive

$13.1(84)$

Unsure

$18.8(120)$

Psychiatrist (\%)

Supportive

$80.9(408)$

Unsupportive

$7.0(35)$

Unsure

General Practitioner (\%)

Supportive

$91.4(601)$

Unsupportive

$2.9(19)$

Unsure

Other mental health professional (\%)

$\begin{array}{ll}\text { Supportive } & 80.2(469) \\ \text { Unsupportive } & 8.5(50) \\ \text { Unsure } & 11.3(66)\end{array}$

${ }^{\mathrm{a}}$ Total numbers vary due to applicability

Entered into regression analyses: ${ }^{\mathrm{b}} \mathrm{Quit}$ attempt in the past 6 months; ${ }^{\mathrm{C}}$ Number of quit attempts in the past 6 months; ${ }^{d}$ Length of longest quit attempt in past 6 months; ${ }^{\mathrm{e}}$ Readiness to quit; ${ }^{\mathrm{f}}$ Ease of seeing oneself as a non-smoker

participants believed that their psychiatrist, GP, or another mental health professional, respectively, would be supportive of them attempting to quit. 


\section{Quitting behaviour and motivations}

Thirty one per cent of participants had attempted to quit in the past six months; with $57 \%$ of those who had done so having made a single quit attempt, and 30 and $13 \%$ having attempted to quit two to three times or more than three times, respectively. Of those who had made a quit attempt in the past six months, $21 \%$ were abstinent for at least one month.

In terms of motivation and readiness to quit, $45 \%$ of participants were assessed as being either contemplative or at a more progressed stage. Forty three percent reported it would be easy to see themselves as a nonsmoker, whereas 43 and $14 \%$ reported it would be difficult or that they were unsure.

\section{Smoking, physical and social and environmental characteristics associated with quitting behaviour and motivation}

Variables with a $p$-value of $\leq 0.25$ in the chi-square analyses and hence entered in the multivariable logistic regression models are noted in Tables 2 and 3. The findings of the five regression models were as follows:

Quit attempt in the past six months: Weekly/irregular smokers were twice as likely as daily smokers to have attempted to quit in the past six months $(O R=2.07$, $95 \%$ confidence interval $(\mathrm{CI}): 1.17$ to $3.64, p<0.05)$ (Table 4). Those who had been smoking for less than 10 years were 1.65 (95\% CI: 1.11 to $2.47, p<0.05$ ) times more likely than those who had smoked for more than 20 years to have attempted to quit in the past six months. Number of quit attempts in the past six months: Smokers who perceived their psychiatrist to be supportive of them quitting smoking were 2.83 (95\% CI: 1.64 to $4.88, p<0.001)$ times more likely than those who perceived their psychiatrist to be unsupportive or who did not have a psychiatrist to have attempted to quit two or more times in the past six months. Duration of quit attempt in the past six months: Smokers of 1-10 cigarettes per day were 16.23 (95\% CI: 2.05 to $128.24, p<0.05)$ times more likely to have made a quit attempt of longer duration, compared to heavier smokers (31 cigarettes or more). Participants not residing with other smokers were 2.02 (95\% CI: 1.002 to $4.06, p<0.05)$ times more likely to have quit for one month or longer in the past six months.

Readiness to quit: Participants who started smoking at the age of 14 or after were 1.40 (95\% CI: 1.04 to 1.87 , $p<0.05)$ times more likely be in the contemplative or a more progressed stage of change, relative to those who initiated smoking prior to the age of 14 .

Identity as a smoker: Weekly/irregular smokers were 2.79 (95 \% CI: 1.47 to $5.29, p<0.05$ ) times more likely than daily smokers to easily see themselves as a non-

Table 4 Multivariable logistic regression results for smoking and physical and social environmental characteristics associated with quitting behaviour and motivation

\begin{tabular}{llllll}
\hline Predictor & $\%(n)$ & OR & & \multicolumn{2}{l}{$95 \% \mathrm{Cl}$} \\
\cline { 5 - 6 } & & & Lower & Upper \\
\hline $\begin{array}{l}\text { Model 1: Quit attempt in the past } 6 \text { months }^{\mathrm{a}} \\
\text { Smoking status }\end{array}$ & & & \\
$\quad$ Weekly/Irregular & $7.0(53)$ & $2.07^{*}$ & 1.17 & 3.64 \\
Daily & $93.0(701)$ & Ref & & \\
Years smoked & & & & \\
$\leq 10$ & $18.3(138)$ & $1.65^{*}$ & 1.11 & 2.47 \\
$11-20$ & $26.9(203)$ & 0.99 & 0.68 & 1.43 \\
$>20$ & $54.8(413)$ & Ref & &
\end{tabular}

Model 2: Number of quit attempts in the past 6 months ${ }^{b}$

Perceived support from psychiatrist

$\begin{array}{lllll}\text { Supportive } & 54.7(128) & 2.83^{* *} & 1.64 & 4.88 \\ \text { Unsupportive/not applicable } & 45.3(106) & \text { Ref } & & \end{array}$

Model 3: Duration of quit attempt in the past 6 months $^{c}$

Lived with smokers

$\begin{array}{lllll}\text { No } & 56.4(132) & 2.02^{*} & 1.002 & 4.06 \\ \text { Yes } & 43.6(102) & \text { Ref } & & \end{array}$

Cigarettes per day

$\begin{array}{lllll}1-10 & 32.9(77) & 16.23^{*} & 2.05 & 128.24 \\ 11-20 & 34.2(80) & 4.23 & 0.52 & 34.61 \\ 21-30 & 21.8(51) & 5.88 & 0.70 & 49.50 \\ 31+ & 11.1(26) & \text { Ref } & & \end{array}$

Model 4: Readiness to quit ${ }^{d}$

Age initiated smoking

$\begin{array}{lllll}\geq 14 \text { years old } & 57.3(432) & 1.40^{*} & 1.04 & 1.87 \\ <14 \text { years old } & 42.7(322) & \text { Ref } & & \end{array}$

Model 5: Identity as a smoker ${ }^{\mathrm{e}}$

Smoking status

Weekly/lrregular

Daily

Nicotine dependence

Low- moderate

High

Number of years smoked

\begin{tabular}{lllll}
$\leq 10$ & $18.3(138)$ & $2.34^{* *}$ & 1.55 & 3.52 \\
$11-20$ & $26.9(203)$ & 1.24 & 0.87 & 1.77 \\
$>20$ & $54.8(413)$ & Ref & & \\
\hline
\end{tabular}

${ }^{a}$ (reference: no); ${ }^{b}$ (reference: one quit attempt; only participants who had attempted to quit were included); ${ }^{c}$ (reference: $<1$ month; only participants who has attempted to quit were included); ${ }^{\mathrm{d}}$ (reference: precontemplative); e(reference: difficult to see self as non-smoker); ${ }^{*} p<0.05,{ }^{* *} p<0.001$; Ref: reference category 
smoker; low-moderate nicotine dependent smokers were 2.34 (95\% CI: 1.72 to $3.18, p<0.001$ ) times more likely to easily see themselves as a non-smoker than highly dependent smokers; and participants who had been smoking for less than 10 years were 2.34 (95\% CI: 1.55 to $3.52, p<0.001)$ times more likely to easily see themselves this way than participants who had smoked for more than 20 years.

\section{Discussion}

This is the first study reporting both the prevalence of a range of smoking and physical and social environmental characteristics of smokers with a mental illness, and the association of such characteristics with quitting behaviour and motivation. In line with previous research, assessment of smoking characteristics indicated a high prevalence of daily smoking, high nicotine dependence and heavy smoking in terms of cigarettes per day; and further, that smoking appeared to be a long-established behaviour. With respect to physical environmental characteristics, smoking was 'present' in the home lives of many participants: nearly one half lived with others who were also smokers and for one third, the home was not smoke-free. Whilst with respect to social environmental characteristics, perceived support for quitting from significant others and health professionals was variable, with a lack of support most evident for friends; one third (32\%) not indicating that friends would be supportive.

The results suggest that despite many participants expressing interest in quitting and making recent quit attempts, reflecting the findings of previous research $[2,12]$, a number of smoking and physical and social environmental characteristics may serve to sustain their tobacco use. In line with the broader smoking literature $[15,16]$ as well as previous research among smokers with a mental illness $[11,22]$, 'lighter' smokers (less nicotine dependent, smoking fewer cigarettes or less than daily) were more likely to have attempted or to be at least contemplating quitting. Such findings suggest a potential benefit of interventions aimed at reducing cigarette consumption among persons with a mental illness in not only decreasing the degree of immediate harm caused by heavy smoking [59] but also increasing the likelihood of subsequent quit attempts and cessation $[4,60]$. The findings that those who had been smoking for a fewer number of years were more likely to envisage life without smoking and to have recently attempted to quit, and that smokers who initiated smoking at a younger age were likely to be less 'ready' to quit, similarly reflects findings from general population smokers [10, 19] and perhaps highlights the importance of providing cessation intervention to young smokers and to all smokers as soon as possible after initiation.

In terms of the physical environment, previous research has reported the presence of smoking in the home environment to be less prevalent among the general Australian population, than for the participants in this study: $34 \%$ [61] (as compared to 44\%) living with another smoker, and only $7 \%$ [62] (as compared to $32 \%$ ) residing in a home that was not smoke free. Further, differences between Australian smokers without a mental illness are also evident in comparison to smokers in the present study: $21 \%$ residing in a home that was not smoke free (as compared to $32 \%$ ), and $42 \%$ of those with a current partner reporting their partner to be a smoker (as compared to $51 \%)$ (International Tobacco Control Policy Evaluation Study: Survey Data, unpublished 2013 and 2014). In line with research undertaken with smokers generally [24, 26, $56]$, the potential influence of other smokers in the immediate environment was indicated by the finding in this study that participants who did not live with other smokers were more likely to have recently made a quit attempt of at least one month duration.

With respect to the social environment, almost all participants (92\%) identified a key support person whom they relied on and/or who routinely provided assistance and support for their well-being and functioning; suggesting the potential to involve support persons, and possibly family carers [63] in smoking cessation interventions. While evidence suggests that involvement of family carers in treatment delivery can be effective in improving mental health outcomes for persons with a mental illness [64], the potential of such carers to support someone with a mental illness to quit smoking appears not to have been explored by research. One U.S. survey of recent quitters with a mental illness does suggest however, that family and friendship networks generally could have a role in encouraging and supporting quitting behaviour [41]. In the present study, while a majority of participants perceived that family, a partner and friends would be supportive of their making a quit attempt, nevertheless quite significant proportions also reported either that such people would be unsupportive of a quit attempt or that they were uncertain of their support (family $18 \%$; partner $29 \%$ and friends $32 \%$ ), indicating a need for further research to explore their potential to play a role in smoking cessation interventions for this group.

The large majority of participants perceived their GP (91\%), psychiatrist (81\%) and other mental health professional/s (80 \%) to be supportive of a quit attempt. Physician advice has been identified to have a particularly positive impact on smoking and quitting behaviour [65] and this was reinforced by the study finding that those participants who perceived psychiatrists as supportive of quitting were more likely to have recently made a greater number of quit attempts. Although the differences in the perceived support across the health professional groups were minimal, 'other' mental health professionals were least likely to be seen as supportive; a finding somewhat reflective of previous 
research suggesting allied health professionals, including psychologists are less likely to routinely assess for or offer intervention for smoking [66], despite the likely efficacy of their doing so [33]. It is possible that higher rates of nicotine dependence reported among some mental health professions, compared to their general health counterparts contributes to a more benign perception of smoking [67] and hence a lower likelihood of intervening. Given the integral role of mental health professionals in caring for persons with a mental illness, and the professional status in particular of psychiatrists, the importance of their accepting provision of smoking cessation care as part of their professional role has been noted previously [68].

The strengths of this study include its conduct with a large and diverse sample of smokers with a mental illness and a relatively high consent rate. However, it is noted that smokers who stayed in the hospital for one night or less and those with psychotic type disorders may be underrepresented, while patients with anxiety/stress and substance-related disorders may be over-represented as compared to aggregate descriptive statistics for the facility's patient population during the recruiting period. The sample consisted of smokers who had consented to take part in an overarching smoking trial and it is unknown whether the prevalence and role of physical and social environmental factors may have differed somewhat for this sample as compared to the broader group of smokers with a mental illness. It is noted that findings need to be interpreted in the context of the cross sectional study design. Future research employing a longitudinal design would add strength to the conclusions that could be drawn. The utilisation of solely self-report data may also pose a limitation, in that accounts of recent quitting behaviour may have been under or over-estimated.

\section{Conclusions}

This paper provides evidence for the importance of considering characteristics of smoking and also of the physical and social environment in cessation interventions for persons with a mental illness. With respect to the latter, it expands previous knowledge in this field in identifying the importance of encouraging physical environments that promote smoking cessation and the potential benefit of engaging significant others and health care providers, particularly psychiatrists.

\section{Availability of supporting data}

The datasets generated and analysed during the current study are not publicly available to preserve the privacy of participants, however are available from the corresponding author on reasonable request.

\section{Competing interests}

The authors declare they have no competing interests.

\section{Authors' contributions}

APM drafted the manuscript and participated in the conception, design and coordination of the study. JAB, JW and PW conceived the study, participated in its design and coordination, and assisted in drafting the manuscript. ES, LM and RC participated in the study design, implementation and interpretation of findings, and assisted with manuscript preparation. LW and MF contributed to the design of the study, interpretation of findings and drafting of the manuscript. TVZ contributed to the analyses, interpretation of findings and manuscript preparation. All authors critically revised and approved the final manuscript for publication.

\section{Acknowledgements}

The authors would like to thank the participants, clinicians and the research team, in particular the recruiting staff, that enabled this study to be undertaken.

Funding

This research was funded by the National Health and Medical Research Council (grant number: G1100130).

\section{Author details}

${ }^{1}$ University of Newcastle, University Drive, Callaghan, NSW 2308, Australia. ${ }^{2}$ Hunter Medical Research Institute, Lot 1 Kookaburra Circuit, New Lambton Heights, NSW 2305, Australia. ${ }^{3}$ Hunter New England Population Health, Longworth Ave, Wallsend, NSW 2287, Australia. ${ }^{4}$ Centre for Translational Neuroscience and Mental Health, Corner Edith and Platt Streets, Waratah, NSW 2298, Australia. ${ }^{5}$ National Drug and Alcohol Research Centre, University of New South Wales, 22-32 King Street, Randwick, NSW 2031, Australia.

Received: 17 December 2015 Accepted: 18 March 2016

Published online: 14 April 2016

\section{References}

1. Lasser K, Boyd W, Woolhandler S, Himmelstein D, McCormick D, Bor DH. Smoking and mental illness: a population based study. JAMA. 2000;284(20): 606-10.

2. McClave AK, McKnight-Eily LR, Davis SP, Dube SR. Smoking characteristics of adults with selected lifetime mental illnesses: results from the 2007 National Health Interview Survey. Am J Public Health. 2010;100(12):2464-72.

3. Lawrence D, Mitrou F, Zubrick SR. Smoking and mental illness: results from population surveys in Australia and the United States. BMC Public Health. 2009:9:285.

4. Royal College of Physicians, Royal College of Psychiatrists. Smoking and mental health. London: RCP Council Report CR178; 2013.

5. Szatkowski $L, M c N e i l l A$. Diverging trends in smoking behaviors according to mental health status. Nicotine Tob Res. 2014;17(3):356-360.

6. de Leon J, Diaz FJ. A meta-analysis of worldwide studies demonstrates an association between schizophrenia and tobacco smoking behaviors. Schizophr Res. 2005;76(2-3):135-57.

7. Colton CW, Manderscheid RW. Congruencies in increased mortality rates, years of potential life lost, and causes of death among public mental health clients in eight states. Prev Chronic Dis. 2006;3(2):A42.

8. Lawrence D, Hancock KJ, Kisely S. The gap in life expectancy from preventable physical illness in psychiatric patients in Western Australia: retrospective analysis of population based registers. BMJ (Clinical Research Ed). 2013;346:f2539.

9. Hymowitz N, Cummings KM, Hyland A, Lynn WR, Pechacek TF, Hartwell TD. Predictors of smoking cessation in a cohort of adult smokers followed for five years. Tob Control. 1997;6 suppl 2:S57.

10. Caponnetto P, Polosa R. Common predictors of smoking cessation in clinical practice. Resp Med. 2008;102(8):1182-92.

11. Prochaska JJ, Hall SE, Delucchi K, Hall SM. Efficacy of initiating tobacco dependence treatment in inpatient psychiatry: a randomized controlled trial. Am J Public Health. 2014;104(8):1557-65.

12. Stockings EA, Bowman J, McElwaine K, Baker A, Terry M, Clancy R, Bartlem K, Wye $P$, Bridge $P$, Knight $J$ et al. Readiness to quit smoking and quit attempts among Australian mental health inpatients. Nicotine Tob Res. 2013;15(5):942-9.

13. van den Putte B, Yzer M, Willemsen MC, de Bruijn GJ. The effects of smoking self-identity and quitting self-identity on attempts to quit smoking. Health Psychol. 2009:28(5):535-44.

14. West R. Theory of Addiction. Oxford: Blackwell; 2006. 
15. Hyland A, Borland R, Li Q, Yong H-H, McNeill A, Fong GT, O'Connor R, Cummings KM. Individual-level predictors of cessation behaviours among participants in the International Tobacco Control (ITC) Four Country Survey. Tob Control. 2006;15 suppl 3:iii83-94.

16. Venters MH, Kottke TE, Solberg LI, Brekke ML, Rooney B. Dependency, social factors, and the smoking cessation process: the doctors helping smokers study. Am J Prev Med. 1990;6(4):185-93.

17. Yong HH, Borland R, Balmford J, Hyland A, O'Connor RJ, Thompson ME, Spittal MJ. Heaviness of smoking predicts smoking relapse only in the first weeks of a quit attempt: findings from the International Tobacco Control Four-Country Survey. Nicotine Tob Res. 2014;16(4):423-9.

18. Messer K, Vijayaraghavan M, White MM, Shi Y, Chang C, Conway KP, Hartman A, Schroeder MJ, Compton WM, Pierce JP. Cigarette smoking cessation attempts among current US smokers who also use smokeless tobacco. Addict Behav. 2015;51:113-9.

19. Hellman R, Cummings KM, Haughey BP, Zielezny MA, O'Shea RM. Predictors of attempting and succeeding at smoking cessation. Health Educ Res. 1991; 6(1):77-86.

20. Khuder SA, Dayal HH, Mutgi AB. Age at smoking onset and its effect on smoking cessation. Addict Behav. 1999;24(5):673-7.

21. John U, Meyer C, Rumpf H-J, Hapke U. Smoking, nicotine dependence and psychiatric comorbidity - a population-based study including smoking cessation after three years. Drug Alcohol Depend. 2004;76(3):287-95.

22. Rohsenow DJ, Tidey JW, Kahler CW, Martin RA, Colby SM, Sirota AD. Intolerance for withdrawal discomfort and motivation predict voucher-based smoking treatment outcomes for smokers with substance use disorders. Addict Behav. 2015;43:18-24

23. Kothari A, Edwards N, Yanicki S, Hansen-Ketchum P, Kennedy MA. Socioecological models: strengthening intervention research in tobacco control. Drogues Santé et Société. 2007;6(1 Suppl 3):iii1-24.

24. Mills Al, Messer K, Gilpin EA, Pierce JP. The effect of smoke-free homes on adult smoking behavior: a review. Nicotine Tob Res. 2009;11(10):1131-41.

25. Nonnemaker J, Hersey J, Homsi G, Busey A, Hyland A, Juster H, Farrelly M. Self-reported exposure to policy and environmental influences on smoking cessation and relapse: a 2-year longitudinal population-based study. Int J Environ Res Public Health. 2011:8(9):3591-608.

26. Osler M, Prescott E. Psychosocial, behavioural, and health determinants of successful smoking cessation: a longitudinal study of Danish adults. Tob Control. 1998;7(3):262-7.

27. McBride CM, Curry SJ, Grothaus LC, Nelson JC, Lando H, Pirie PL. Partner smoking status and pregnant smoker's perceptions of support for and likelihood of smoking cessation. Health Psychol. 1998;17(1):63-9.

28. Wagner J, Burg M, Sirois B. Social support and the transtheoretical model: Relationship of social support to smoking cessation stage, decisional balance, process use, and temptation. Addict Behav. 2004;29(5):1039-43.

29. Stewart DW, Thomas JL, Copeland AL. Perceptions of Social Support Provided to Smokers. J Smok Cessat. 2010;5(01):95-101.

30. Bao Y, Duan N, Fox SA. Is some provider advice on smoking cessation better than no advice? An instrumental variable analysis of the 2001 National Health Interview Survey. Health Serv Res. 2006;41(6):2114-35.

31. Fichtenberg CM, Glantz SA. Effect of smoke-free workplaces on smoking behaviour: systematic review. BMJ. 2002;325:188.

32. Park EW, Tudiver F, Schultz JK, Campbell T. Does enhancing partner support and interaction improve smoking cessation? A meta-analysis. Ann Fam Med. 2004;2(2):170-4.

33. Mojica WA, Suttorp MJ, Sherman SE, Morton SC, Roth EA, Maglione MA, Rhodes SL, Shekelle PG. Smoking-cessation interventions by type of provider: a meta-analysis. Am J Prev Med. 2004;26(5):391-401.

34. May S, West R. Do social support interventions ("buddy systems") aid smoking cessation? A review. Tob Control. 2000;9(4):415-22.

35. Aschbrenner KA, Ferron JC, Mueser KT, Bartels SJ, Brunette MF. Social predictors of cessation treatment use among smokers with serious mental illness. Addict Behav. 2015;41:169-74.

36. King BA, Patel R, Babb SD. Prevalence of smokefree home rules-United States, 1992-1993 and 2010-2011. Morb Mortal Wkly Rep. 2014;63(35):765-9.

37. Okoli CT, Johnson JL, Malchy L. Correlates of secondhand tobacco smoke exposure among persons with severe and persistent mental illness (SPMI) accessing community mental health services. Community Ment Health J. 2009;45(3):188-98.

38. Bowden JA, Miller CL, Hiller JE. Smoking and mental illness: a population study in South Australia. Aust N Z J Psychiatry. 2011;45(4):325-31.
39. Ferron JC, Brunette MF, He X, Xie H, McHugo GJ, Drake RE. Course of smoking and quit attempts among clients with co-occurring severe mental illness and substance use disorders. Psychiatr Serv. 2011;62(4):353-9.

40. Dickens GJ, Stubbs JH, Popham R, Haw C. Smoking in a forensic psychiatric service: a survey of inpatients' views. J Psychiatr Ment Health Nurs. 2005;12:672-8.

41. Dickerson F, Bennett M, Dixon L, Burke E, Vaughan C, Delahanty J, Diclemente C. Smoking cessation in persons with serious mental illnesses: the experience of successful quitters. Psychiatr Rehabil J. 2011;34(4):311-6.

42. Nawaz S, Frounfelker R, Ferron JC, Carpenter-Song EA, Davis K, Brunette MF. Smoking and quitting beliefs, attitudes, and behaviors among smokers with severe mental illness from three race/ethnicity groups. J Dual Diagn. 2012;8(3):180-7.

43. Morris CD, Waxmonsky JA, May MG, Giese AA. What do persons with mental illnesses need to quit smoking? Mental health consumer and provider perspectives. Psychiatr Rehabil J. 2009;32(4):276-84.

44. Howard LM, Bekele D, Rowe M, Demilew J, Bewley S, Marteau TM. Smoking cessation in pregnant women with mental disorders: a cohort and nested qualitative study. BJOG. 2013;120(3):362-70.

45. Kerr S, Woods C, Knussen C, Watson H, Hunter R. Breaking the habit: a qualitative exploration of barriers and facilitators to smoking cessation in people with enduring mental health problems. BMC Public Health. 2013;13:221.

46. Lawn SJ, Pols RG, Barber JG. Smoking and quitting: a qualitative study with community-living psychiatric clients. Soc Sci Med. 2002;54(1):93-104.

47. Goldberg JO, Moll S, Washington A. Exploring the challenge of tobacco use and schizophrenia. Psychiatr Rehab Skills. 1996;1(2):55-67.

48. Rose JS, Chassin L, Presson CC, Sherman SJ. Prospective predictors of quit attempts and smoking cessation in young adults. Health Psychol. 1996;15(4):261-8.

49. Metse AP, Bowman JA, Wye P, Stockings EA, Adams M, Clancy R, Terry M, Wolfenden L, Freund M, Allan J et al. Evaluating the efficacy of an integrated smoking cessation intervention for mental health patients: study protocol for a randomised controlled trial. Trials. 2014;15(1):266.

50. Bradley KA, DeBenedetti AF, Volk RJ, Williams EC, Frank D, Kivlahan DR. AUDIT-C as a brief screen for alcohol misuse in primary care. Alcohol Clin Exp Res. 2007;31(7):1208-17.

51. Heatherton TF, Kozlowski LT, Frecker RC, Fagerstrom K-O. The Fagerstrom Test for Nicotine Dependence: a revision of the Fagerstrom Tolerance Questionnaire. Br J Addict. 1991;86(9):1119-27.

52. Stockings EA, Bowman J, Baker AL, Terry M, Clancy R, Wye P, Knight J, Moore L, Adams $\mathrm{M}$, Colyvas $\mathrm{K}$ et al. Impact of a post-discharge smoking cessation intervention for smokers admitted to an inpatient psychiatric facility: a randomised controlled trial. Nicotine Tob Res. 2014;16(11):1417-28.

53. Crittenden KS, Manfredi C, Lacey L, Warnecke R, Parsons J. Measuring readiness and motivation to quit smoking among women in public health clinics. Addict Behav. 1994;19(5):497-507.

54. Corp IBM. IBM SPSS Statistics for Windows, Version 22.0. Armonk: IBM Corp.; 2013.

55. Hyland A, Laux FL, Higbee C, Hastings G, Ross H, Chaloupka FJ, Fong GT, Cummings KM. Cigarette purchase patterns in four countries and the relationship with cessation: findings from the International Tobacco Control (ITC) Four Country Survey. Tob Control. 2006;15 Suppl 3:iii59-64.

56. Siahpush M, Borland R, Scollo M. Factors associated with smoking cessation in a national sample of Australians. Nicotine Tob Res. 2003; 5(4):597-602.

57. Nicholson AK, Borland R, Davey ME, Stevens M, Thomas DP. Predictors of wanting to quit in a national sample of Aboriginal and Torres Strait Islander smokers. Med J Aust. 2015;202(10):S26-32.

58. Fagerstrom KO, Heatherton TF, Kozlowski LT. Nicotine addiction and its assessment. Ear Nose Throat J. 1991;69:763-5.

59. Kelly DL, McMahon RP, Wehring HJ, Liu F, Mackowick KM, Boggs DL, Warren KR, Feldman S, Shim JC, Love RC et al. Cigarette smoking and mortality risk in people with schizophrenia. Schizophr Bull. 2011;37(4): 832-8.

60. Evins AE, Cather C, Rigotti NA, Freudenreich O, Henderson DC, Olm-Shipman CM, Goff DC. Two-year follow-up of a smoking cessation trial in patients with schizophrenia: increased rates of smoking cessation and reduction. J Clin Psychiatry. 2004;65(3):307-11. quiz 452-303.

61. Australian Institute of Health and Welfare (AlHW). Australia's health 2008. AlHW Cat no. AUS 99. Canberra: AlHW; 2008.

62. Centre for Epidemiology and Research. Report on Adult Health from the New South Wales Population Health Survey. Sydney: NSW Department of Health; 2010. p. 2011.

63. New South Wales Department of Health. NSW Carers Action Plan 2007-2012. North Sydney: State Government of New South Wales; 2007. 
64. Harvey C, O'Hanlon B. Family psycho-education for people with schizophrenia and other psychotic disorders and their families. Aust N Z J Psychiatry. 2013; 47(6):516-20.

65. Stead LF, Bergson G, Lancaster T. Physician advice for smoking cessation. Cochrane Database Syst Rev. 2008;2:CD000165.

66. Akpanudo SM, Price JH, Jordan T, Khuder S, Price JA. Clinical psychologists and smoking cessation: treatment practices and perceptions. J Commun Health. 2009;34(6):461-71.

67. Connolly M, Floyd S, Forrest R, Marshall B. Mental health nurses' beliefs about smoking by mental health facility inpatients. Int J Ment Health Nurs. 2013;22(4):288-93.

68. Williams JM, Stroup TS, Brunette MF, Raney LE. Tobacco use and mental illness: a wake-up call for psychiatrists. Psychiatr Serv. 2014;65(12):1406-8.

Submit your next manuscript to BioMed Central and we will help you at every step:

- We accept pre-submission inquiries

- Our selector tool helps you to find the most relevant journal

- We provide round the clock customer support

- Convenient online submission

- Thorough peer review

- Inclusion in PubMed and all major indexing services

- Maximum visibility for your research

Submit your manuscript at www.biomedcentral.com/submit 